\title{
Research on the Problems and Countermeasures of the Construction of University Archive Information
}

\author{
Shumin Cui \\ Management of teaching and research base, \\ Jilin Agricultural University, \\ Changchun, China \\ Email: cuishuminc@126.com
}

Key words: archive; information construction; countermeasures

\begin{abstract}
The archive information is the inevitable product of adaptation to the development of information society and the inevitable choice for archives to adapt to the times and social development. It will have far-reaching implications to the education and scientific research of universities to accelerate information construction of university archives and greatly develop and use archival resources. This paper points out the current situation of construction of archival information, and discusses the countermeasures to accelerate the pace of information technology of university archives based on the discussion of the necessity of the information construction of university archives.
\end{abstract}

\section{Introduction}

In nowadays society, information technology penetrates into all aspects of social activities and all areas are faced with the situation of accelerated information process, especially the archives information. As a true record of human social activities, archives will change inevitably in the process of formation, transmission, storage and utilization along with the changing times. Archival work is an important part of college management, which carries school history, the human spirit, campus culture, scientific literacy, etc. It plays a background and safeguarding role in colleges and universities and reflects the modern management level of the university to a certain extent. The main task of current university archive management is to make full use of information technology to promote the construction of archival information, to explore and utilize archival information resources, to reform archive management and service mechanism, and to meet the needs of teaching, research and management and so on. It brings opportunities and challenges to the innovation of the model of university archival management and the reform of working mechanism that accelerating the process of university archival informatization and the construction of digital archive based on digital campus environment.

\section{The necessity of the construction of university archive information}

A. The construction of archive information is the need for social development

With the accelerating of social progress, scientific development, and office automation process, the construction of university archive information has developed to a new historical stage. The traditional manual, sorting methods, physical preservation methods of paper archives, labor search, query and other means have been gradually replaced by modern management mode. Information technology has penetrated into teaching, research and every aspect of management. Archive information has become an inevitable trend of university archives development ${ }^{[1]}$. 


\section{B. The service areas of archival work can be expanded.}

Archive information will provide a lot of basic public native information to society which is necessary and reliable. It can meet the needs of people to share information and provide the basic conditions for the development and utilization of public information. It also lays foundation for the information society. Moreover, the application of modern management tools to store all kinds of information is more convenient for the development and use, which can also produce a wider range of social benefits and greatly expand the service areas of archival work.

\section{It can greatly improve the efficiency of archive management}

Under information environment, paper documents and electronic filing are necessarily processed efficiently and orderly under the new management model. The part-time archivists of all sectors in the school use the network to send and receive files and input or upload the disposed files into archive management software. Archives staffs inspect and accept the data into the system ${ }^{[2]}$. By using the electronic files and paper records produced by the automatic archiving of archive management system, the workload of entry is reduced and the cycle of archive formation and utilization is shorten and the work efficiency is also improved.

\section{It can integrate with the university office automation system}

With the development of modern information technology and construction of digital campus, campus network has been commonly set up in the university. The use of network enables the efficient integration of archive management system and school office automation system and the timely reception of the more standardized electronic document information formed directly in the office automation process. These data will directly turn into digital archive. Archives should effectively manage and optimize the file information resources.

\section{The current situation of the university archives}

\section{A. The current management methods and concepts do not coordinate with the current development of information}

The construction of university archive information include the digital construction of archive resources, the construction of archive information database, the orderly organization of archival information resources, the development and utilization of archival information resources, and the cultivation of archival talents. The archival management ideas and ways and means have not been separated from the traditional archive work. According to the study learnt by the author, part of the university's archive work still adopts the traditional manual paper-based management. The artificial notes, classification and statistics of some archival information make the overall efficiency of archive management is low and error-prone ${ }^{[3]}$. In addition, the construction of archive information has been implemented in most universities. However, due to the staff's following the traditional pattern of archive management and unfamiliarity with the current information technology means, the archive information pattern is hard to become the mainstream mode of archival work, resulting in the lag of the construction of archive information and the incoordination with the current development trend of information technology.

\section{B. The archive information level is not balanced and low overall}

In recent years, driven by the digital campus, the construction of university archive information has been developed quickly. But on the whole situation, the development of university archive information is not balanced and low overall. Affected by various subjective and objective factors, the development of university archive information is also different in different universities. The archive management methods and techniques still rely on traditional paper-based records management and the working mode is still mainly about entity archive. Although the computer and information technology are already adopted as aided management, most is limited to the information management of archive directory. The information management of the full text of archive is still in its infancy and information technology is behind the development of the times. 
Measured by taking the digital archives and archive knowledge service system as the development goals, there is still much room for the development of university archive information ${ }^{[4]}$.

\section{The infrastructure of realizing digital archive is still not mature enough}

Infrastructure is an important security condition for the archive management information which must be greatly strengthened. Improve the hardware and software environment conditions to realize the standardization and scientificity of archive management. Strengthen sense of innovation and apply advanced technology. Implement archive system innovation and establish a sound mechanism to deal with the great development environment of information.

\section{The countermeasures of the construction of university archive information}

\section{A. Raise the awareness of archive information and strengthen ideas of information}

We must fully recognize the value, status, role and significance of university archives and be aware of the importance and necessity of the construction of university archive information. The quality of the construction of archive information is an important benchmark to measure the level of university modernization. The better construction of university archive information can promote the comprehensive development of university. Strengthen ideas of information on the basis of raising the awareness. Establish the international concept, innovative concept, service concept, and legal concept and guide the construction of university archive information with the new concepts.

\section{B. Strengthen university archives standardization and standardize research archives information of higher education}

Standardization is the premise of automation and networking. The network coordinating institutions of university archives department should convene the related experts to discuss and formulate the harmonized principles and norms of the related operational work, technical methods and equipment and so on. In accordance with international and national standards and industry trends, work out the standard network that should be abided by universities and community as well as the internal universities during the process of the standard network. Establish a set of electronic records management database which is qualified for archive information work so as to avoid detours during the transition to resource sharing and avoid the waste of manpower, material and financial resources.

\section{Develop archive resources and strengthen the building of database}

Database is an important part of the construction of archive network and the information resource of network. To strengthen the network construction, we must strengthen the construction of database. The construction of database should base on international and national criteria and concentrate manpower, material and financial resources to build a number of file entry databases, full-text databases, multimedia databases of high standard and versatility. Accelerate the establishment of archive catalog center and enrich resource reserves of archival data. Provide strong back-end database support for archive information and do a solid bibliographic work of archives. Moreover, strengthen the maintenance work of the database and ensure data integrity and quality. Pay close attention to the standardization of small database of the sector and increase database capacity and improve the access rate of database ${ }^{[5]}$.

\section{Strengthen personnel training and improve the overall quality}

Actively introduce archive management professionals and computer professionals and optimize the structure of archive personnel by training, introduction and personnel flow, and so on. It is the important foundation and effective protection for the construction of university archive information to cultivate an innovative team of high professional quality and comprehensive strength combining managerial, technical, service-oriented, and research pattern. Computer professionals should be equipped for archives departments if the condition is permitted to better complete the construction of archival information. Improve earnestly the quality of full-time and part-time archivists. Improve the technology application ability of modern information of full-time and 
part-time archivists through various training ways and build a team of full-time and part-time archivists who possess sense of strong responsibility, excellent technology, and are adapt to the needs of information management.

\section{E. Strengthen the establishment of security system of university archive information}

University archive information security is a systematic project. If there is no effective safety management, any other efforts would be useless. The archive information security requires a comprehensive security management system and needs to develop a set of appropriate norms from the aspects of safety management organization, system, and the measure. Adhere to the principle of laying equal stress on both use and secret and take effective technical means and management measures. Strictly ensure authentication and key management to make sure the security and confidentiality of information and the reliability of the operation of system. The realization of archive information security measures and college network security systems can be considered together in order to save human and financial resources.

\section{Conclusion}

The impact of archive information on education and scientific research of universities is far-reaching. The construction of archive information is imperative. We need to confront the current difficulties and existing problems and seize opportunities. Build up confidence and confront difficulties. Invest human, material and financial resources of the greatest possibility starting from the infrastructure and take effective measures to realize the construction of archive information. The future development direction of university is to strive to build a service-oriented digital archive, namely the digitization and networking of archive information, the integration of archive information management and providing usage, high degree sharing of archive information. Ensure archive security and regulate the university archive information.

\section{References}

[1] Chen Meiqiong. The current situation and countermeasures of the university archive information in information society. [J]. Journal of Fuqing branch of Fujian Normal University, 2009 (3).

[2] Wang Yamin. On the countermeasures of university archive management under information. [J]. China archieves, 2009(5).

[3] Zhi Tonghai. On Problems and Countermeasures in the construction of university archive information. [J]. Journal of Yancheng Institute of technology, 2011 (2):90

[4] Cao Qinmin. From the "exclusive" to "shared"------ On the path of realizing the social value university archive information. [J]. Archives Science Bulletin, 2012 (5): 49-52.

[5] Luo Baoyong. On the historical review and reflection on Chinese Digital Archives Research. [J]. Archives Science Bulletin, 2012 (5): 63-66. 